\title{
RETRACTED ARTICLE: Molecular cloning and expression analysis of novel putative effector genes from Meloidogyne graminicola
}

\author{
Masuder Rahman • Annelies Haegeman • \\ Bytul M. Rahman • Godelieve Gheysen
}

Received: 30 April 2013 /Revised: 9 June 2013 / Accepted: 19 June 2013 /Published online: 12 July 2013

(C) Institute of Plant Genetics, Polish Academy of Sciences, Poznan 2013

The authors in agreement with the Editor-in-Chief wish to retract this article because it was submitted without approval by the complete research team. Moreover, the senior researchers who were unaware of this paper being submitted by MSc student Masuder Rahmann to the "Journal of Applied Genetics" already published a large part of the results in "Identification of candidate effector genes in the transcriptome of the rice root knot nematode Meloidogyne graminicola" by Haegeman A, Bauters L, Kyndt T, Rahman MM, Gheysen G; Molecular Plant Pathology, 2013, 14(4), 79-90. doi:10.1111/mpp.12014.

The authors in agreement with the Editor-in-Chief wish to retract this article because it was submitted without approval by the complete research team. Moreover, the senior researchers who were unaware of this paper being submitted by MSc student Masuder Rahmann to the "Journal of Applied Genetics" already published a large part of the results in "Identification of candidate effector genes in the transcriptome of the rice root knot nematode Meloidogyne graminicola" by Haegeman A, Bauters L, Kyndt T, Rahman MM, Gheysen G; Molecular Plant Pathology, 2013, 14(4), 79-90. doi:10.1111/mpp.12014.

M. Rahman $(\bowtie)$

Department of Biotechnology and Genetic Engineering, Mawlana Bhashani Science \& Technology University, Santosh,

Tangail 1902, Bangladesh

e-mail: masudmbstu@gmail.com

M. Rahman • A. Haegeman • G. Gheysen

Department of Molecular Biotechnology, Ghent University,

Ghent 9000, Belgium

B. M. Rahman

Department of Pharmacy, University of Rajshahi, Rajshahi 6205,

Bangladesh 